\title{
Vital Signs Position
}

National Cancer Institute

\section{Source}

National Cancer Institute. Vital Signs Position. NCI Thesaurus. Code C83114.

The physical bearing of the body during a vital signs assessment. 